\title{
Is active surveillance a safe alternative in the management of localized prostate cancer? Pathological features of radical prostatectomy specimens in potential candidates for active surveillance
}

Zambrano Norman, Petric Militza, Figueroa Andrés, Fleck Daniela, Mercado Alejandro, Sanchez Catherine, Fullá Juan

Department of Urology, Clinica Las Condes (ZN, FD, MA, SC, FJ); Department of Urology, Hospital Militar (ZN, PM, FA); Department of Urology, University of Chile Clinical Hospital (MA) and Department of Urology, San Borja Hospital (FJ), Santiago, Chile

\section{ABSTRACT}

Introduction and objective: Active surveillance (AS) has become an accepted alternative for patients with low risk prostate cancer. The purpose of AS is to defer definitive therapy in these patients to avoid treatment-related complications. Our aim was to determine the pathological features of the surgical specimen from potential AS candidates that underwent radical prostatectomy (RP).

Materials and Methods: We retrospectively reviewed a group of patients submitted to RP who met criteria for AS: Gleason score $(\mathrm{GS}) \leq 3+3=6$, PSA $\leq 10 \mathrm{ng} / \mathrm{mL}$, T1c $-\mathrm{T} 2 \mathrm{a}$, $<1 / 3$ of positive cores, $<50 \%$ of involvement in any core and PSA density $<0.15$. We determined the concordance between GS in biopsy and RP specimen (RPS). Other pathological features of the RPS were also analyzed, including surgical margins, extracapsular extension, seminal vesicles and lymph node involvement.

Results: We identified 167 patients subjected to RP that met the criteria for AS. Fifty two patients (31.1\%) had a GS > 6 in the RPS (GS $7 \mathrm{n}=49$; GS $8 \mathrm{n}=3$ ). Extracapsular extension, seminal vesicle and lymph node involvement was found in $6.1 \%, 3.1 \%$ and $1.2 \%$ of the specimens, respectively.

Conclusion: In this study a significant proportion of potential candidates for AS showed features of aggressive and/or high-risk tumors in the RPS. Therefore, before considering a patient for an AS protocol, a proper and strict selection must be performed, and informed consent is crucial for these patients.

\section{ARTICLE INFO}

\section{Key words:}

Prostatic Neoplasms:

Active surveillance;

Prostatectomy

Int Braz J Urol. 2014; 40: 154-60

Submitted for publication:

March 25, 2013

Accepted after revision:

January 21, 2014

\section{INTRODUCTION}

Prostate cancer $(\mathrm{PCa})$ is a significant public health problem in the occidental world and is one of the most important death causes in men over 50 years (1). The extension of the tu- mor at the moment of diagnosis is determinant of patient's survival (2). The massive use of prostate specific antigen (PSA) has significantly increased the number of tumors diagnosed at early stages, but has also led to over-diagnosis and over-treatment of a considerable number of patients with 
clinically insignificant PCa (3). Active surveillance (AS) is an accepted alternative for the management of patients with low risk PCa (4).

The purpose of AS is to defer definitive treatment with a strict follow-up including clinical visits every 3 months with digital rectal examination (DRE) and PSA measurements. An annual biopsy is also advised. Definitive treatment should be offered to those men with evidence of progression (5). The actual criteria for AS vary between different clinical centers. The most accepted criteria for including a patient with PCa to an AS protocol are: clinical stage $\mathrm{T} 1 \mathrm{c}$ or $\mathrm{T} 2, \mathrm{GS} \leq 3+3=$ 6 , PSA $\leq 10 \mathrm{ng} / \mathrm{mL}, \leq 2$ positive cores and $<50 \%$ involvement in each core (6).

Most of the criteria accepted for including a patient into an AS protocol are based in pathological characteristics of preoperative transrectal biopsy. However, different studies report a GS up-grade in 24-39\% of the surgical specimens when compared to preoperative biopsy (5). This means that a proportion of patients selected for an AS protocol may carry a higher risk disease not detected in the transrectal biopsy specimen. It is known that by increasing the number of cores in the transrectal biopsy, the correlation between the preoperative and postoperative findings improves (7). We do not know what is the percentage of Gleason score undergrading in our center, so without this data, active surveillance would not be a safe alternative management. The aim of our study was to determine the pathological features of the surgical specimen from potential AS candidates that underwent radical prostatectomy and compare them with the results of their pre-operative transrectal biopsies, and thus answer the question if active surveillance is a safe management alternative for prostate cancer.

\section{MATERIALS AND METHODS}

\section{Patients}

We conducted a retrospective study that included 167 latin-american patients from a group of 623 subjected to RP at two institutions from 2008 to 2011. These patients could have been candidates for AS since they fulfilled the following criteria: $\mathrm{GS} \leq 3+3=6$, T1c $-\mathrm{T} 2 \mathrm{a},<\mathrm{n}=4$ positive.
Less than $1 / 3$ of cores and/or no more than $n=3$ cores involved, $<50 \%$ of compromise in any core of the transrectal biopsy, PSA level $\leq 10 \mathrm{ng} / \mathrm{mL}$ and PSA density < 0.15 (8). PSA density was calculated by dividing the absolute PSA value by the prostatic weight assessed by transrectal ultrasound. Informed consent was obtained from each patient.

\section{Histological study}

Pre-surgical prostatic biopsy and radical prostatectomy specimen (RPS) samples from the 167 patients were analyzed by different pathologists in two medical centers. Surgical specimens were evaluated using the Gleason grading system. Extraprostatic extension, when present, was subclassified as being either focal or extensive. Surgical resection margins were designated as being positive or negative. Seminal vesicle involvement was considered to be present upon penetration of the tumor into the muscular coat of the seminal vesicle.

\section{Statistical analysis}

The percent of upgrading and downgrading of the surgical specimen was determined by comparing GS of biopsy and RPS. The data were tabulated and analyzed using the SPSS v17.0 software (IBM, USA). A chi square (X2) statistic was used to investigate whether distributions of categorical variables differ from one another considering a $\mathrm{p}$ value $<0.05$ statistically significant.

\section{RESULTS}

\section{Patients}

Of 623 patients subjected to RP between 2008 and 2011, 167 fulfilled criteria and therefore could have been candidates for AS. Patient characteristics are showed in Table-1. The mean age in this group was 62.3 years (40-75) and the mean PSA value was $5.9 \mathrm{ng} / \mathrm{mL}$ (0.59-10). Regarding to clinical stage, $74.2 \%(n=124)$ corresponded to T1c and 25.7\% $(\mathrm{n}=43)$ to T2a.

All patients had preoperatory biopsy that was performed 4-8 weeks before surgery. All patients included in the study had GS $\leq 6$ in pre-operative biopsy. From these, most patients (89.2\%) had a GS of 6. In the surgical specimen, the num- 
Table 1 - Pre-operative clinical and pathological features.

\begin{tabular}{|c|c|}
\hline Mean age in years (range) & $62.3(40-75)$ \\
\hline $\begin{array}{l}\text { Mean pre-operative PSA in } \mathrm{ng} / \mathrm{mL} \\
\text { (range) }\end{array}$ & $5.9(0.59-10)$ \\
\hline Average PSA Density (range) & $0.146(0.07-0.149)$ \\
\hline \multicolumn{2}{|l|}{ Clinical Stage (\%) } \\
\hline T1c & $124(74.3 \%)$ \\
\hline $\mathrm{T} 2 \mathrm{a}$ & $43(25.7 \%)$ \\
\hline \multicolumn{2}{|l|}{ Transrectal Biopsy Characteristics } \\
\hline Mean number of cores (range) & $17.1(8-24)$ \\
\hline $\begin{array}{l}\text { Mean Percent (\%) of core } \\
\text { involvement (range) }\end{array}$ & $12 \%(2-49 \%)$ \\
\hline Preoperative biopsy Gleason score & $\mathrm{n}(\%)$ \\
\hline 3 & $1(0.6)$ \\
\hline 4 & $10(6)$ \\
\hline 5 & $7(4.2)$ \\
\hline 6 & $149(89.2)$ \\
\hline \multicolumn{2}{|l|}{ Postoperative Gleason score $n(\%)$} \\
\hline 3 & $1(0.6)$ \\
\hline 4 & $5(3)$ \\
\hline 5 & $1(0.6)$ \\
\hline 6 & $101(60.5)$ \\
\hline 7 & $49(29.3)$ \\
\hline$(3+4)$ & $40(23.9)$ \\
\hline$(4+3)$ & $9(5.4)$ \\
\hline 8 & $3(1.8)$ \\
\hline High grade PIN & $5(3)$ \\
\hline Benign Prostatic Hyperplasia & $2(1.2)$ \\
\hline Upgrading in the RPS & $52(31.1)$ \\
\hline
\end{tabular}

ber of patients with GS 6 decreased to 60.5\%, and fifty two patients (32.2\%) had a GS > $6(29.3 \%$ GS $7 \mathrm{n}=49 ; 1.8 \%$ GS $8 \mathrm{n}=3$ ) (Table-1).

When we performed an analysis of the clinical characteristics of the subgroup of patients with GS > 6 in the RPS, we observed a significant difference with respect to age (61.7 vs. 63.5 years; $\mathrm{p}=0.024$ ), not so with the PSA level (5.81 vs. 6.31 $\mathrm{ng} / \mathrm{ml} ; \mathrm{p}=0.93$ ) in comparison to the group with $\mathrm{GS}<$ or $=$ to 6 in the RPS.

\section{RPS}

Table-2 summarizes pathological features of the surgical specimen. Positive surgical margins, extracapsular extension, seminal vesicle and lymph node involvement were reported in 30.7\%, 6.1\%, $3.1 \%$ and $1.2 \%$, respectively. Table- 3 shows a comparison between patients with clinical stage T1c and T2a regarding to pathological features of the surgical specimen. Thirty percent of patients with a clinical stage T1c had a GS > 6 in the surgical specimen, compared to a 58.1\% of patients with a clinical stage T2a $(\mathrm{p}<0.001)$. No other pathological differences (tumor volume, extracapsular extension, positive surgical margins, seminal vesicles involvement and lymph node involvement) were found. By using Epstein criteria for insignificant cancer (tumor volume $<0.2 \mathrm{~cm}^{3}$, organ confined disease and no Gleason pattern 4 or 5), only 16 $(9.6 \%)$ patients were classified as such.

\section{DISCUSSION}

PCa is a significant public health problem in the occidental world, and one of the most important death causes in men over 50 years (1). In Chile, the mortality from PCa has steadily increased in the last decades reaching a rate of 20.9 per 100,000 men in year 2009, ranking in the second place of cancer death causes in men, producing approximately 1,753 deaths per year (9). The extension of the tumor at the time of diagnosis is determinant of patient's survival (2).

Independent of the controversies, PSA screening programs lead to an early detection of $\mathrm{PCa}$ in men, thereby substantially reducing their morbidity and mortality as showed by the Goteborg study and the European Randomized Study 
Table 2 - Anatomopathological features of the surgical specimen.

\begin{tabular}{lc}
\hline & Frequency (\%) \\
\hline Median Tumor Volume (cc) & 1.37 \\
Extracapsular extension & $11(6.1)$ \\
Seminal Vesicle Involvement & $5(3.1)$ \\
Lymph Node Involvement & $2(1.2)$ \\
\hline
\end{tabular}

of Screening for Prostate Cancer (ERSPC) $(10,11)$. The massive use of PSA in the clinical practice has significantly increased the number of tumors diagnosed in early stages, leading to an over-diagnosis and over-treatment of clinically insignificant PCa (3). Recent studies have demonstrated that to save one life from prostate cancer is necessary to treat 48 men with a follow-up of at least 9 years (12).

The basis of AS is a careful selection of patients that can defer immediate treatment as they have a localized, well-differentiated and therefore low-risk PCa (13). Some centers recommend a 3-monthly follow-up with DRE and PSA, and a transrectal prostate biopsy every one or two years. In those patients in whom PCa progression is detected, definitive therapy has to be offered (5).

The actual criteria for the selection of patients for AS vary according to the urological center. A recent review of Conti et al. showed that those institutions with more strict inclusion crite- ria (including estimation of tumor volume based on the number and percent of cores compromised) had less adverse results in the surgical specimen (less percent of seminal vesicle involvement and/ or extracapsular extension) (14).

Thaxton et al. published a study showing the pathological features of the surgical specimen from patients that fulfilled criteria for AS but otherwise were subjected to RP. From these patients 4\% had a GS between 8 and 10, 5\% had seminal vesicle involvement and up to $1 \%$ had lymph node involvement. This study concluded that the most important predictor of unfavorable outcome was a GS > 6 (15). Beauval JB et al. demonstrated that despite of a stringent selection of patients with low-risk prostate cancer, active surveillance definition included a significant proportion of patients with upstaged (about 12\%) and upgraded (about one-third) disease at diagnosis (16). In this same sense Iremashvili studied the ability of contemporary AS criteria to identify patients with certain pathologic tumor features based on the results of an extended transrectal prostate biopsy. The authors concluded that significant variations exist in the ability of contemporary AS criteria to predict pathologically insignificant prostate cancer at radical prostatectomy (17).

In our experience, a high proportion of patients (31.1\%) that were candidates for AS had a GS $>6$ and also had pathological features of unfavorable outcome: extracapsular extension (6.1\%), seminal vesicle (3.1\%) or lymph node involvement

Table 3 - Anatomopathological features of the surgical specimen. Comparison between T1c and T2a.

\begin{tabular}{lccc}
\hline & \multicolumn{2}{c}{ Clinical Stage } & P value \\
\hline & T1c & T2a & \\
\% of Patients with GS $>$ in RPS & $29.9 \%$ & $58.1 \%$ & $\mathrm{p}<0.001$ \\
Mean tumor volume (cc) & 2.02 & 2.7 & 0.181 \\
Extracapsular Extension & $5.3 \%$ & $10.3 \%$ & 0.28 \\
Positive Surgical Margins & $28.8 \%$ & $37.2 \%$ & 0.3 \\
Seminal Vesicle Involvement & $3.4 \%$ & $2.3 \%$ & 0.73 \\
Lymph Node Involvement & $0.8 \%$ & $1.2 \%$ & 0.45 \\
\hline
\end{tabular}


(1.2\%). The proportion of patients with GS > 6 was significantly higher in patients with clinical stage T2a compared to T1c $(\mathrm{P}<0.001)$. No other differences were found in relation to clinical stage. Several factors can influence the likelihood that the biopsy GS underestimates the prostatectomy score, including the PSA level, the level of pathologist expertise, the patient's age, the results of the digital rectal examination, the prostate gland volume, the percentage of cancer cells in the biopsy sample and the number of biopsies obtained $(18,19)$.

The main limitations of the study were the retrospective design and that both biopsy and prostatectomy specimens were examined by different pathologists.

Another reason why the under-grading can occur is the presence of an anterior prostate cancer, which are less likely to be palpable and required more prostate biopsies than posteriorly located prostate cancers (PPCs) (20).

These results suggest that the selection criteria for AS have to be discussed and adjusted to the reality of each center. In our opinion, reliability of pathological findings in the pre-operative biopsy is of striking importance and efforts should be made to improve a correct pathological diagnosis. Until now, AS programs needs longer follow-up to prove that they are an appropriate and safe alternative for the management of patients with prostate cancer.

\section{CONCLUSIONS}

Patients with clinical T1c tumors were significantly less under-graded than T2a. However, a significant proportion of patients that could have been considered for AS, had tumors with unfavorable features (high GS, extracapsular extension, seminal vesicle and lymph-node involvement). In these cases, delay of definitive therapy could determine a lower survival rate. Therefore, before considering a patient for an AS protocol, a proper and strict selection must be performed, and informed consent is crucial for these patients.

\section{CONFLICT OF INTEREST}

None declared.

\section{REFERENCES}

1. Jemal A, Bray F, Center MM, Ferlay J, Ward E, Forman D: Global cancer statistics. CA Cancer J Clin. 2011; 61: 69-90. Erratum in: CA Cancer J Clin. 2011; 61: 134.

2. Grönberg H: Prostate cancer epidemiology. Lancet. 2003; 361: 859-64.

3. Bastian PJ, Carter BH, Bjartell A, Seitz M, Stanislaus P, Montorsi $F$, et al.: Insignificant prostate cancer and active surveillance: from definition to clinical implications. Eur Urol. 2009; 55:1321-30.

4. D'Amico AV, Whittington R, Malkowicz SB, Schultz D, Blank K, Broderick GA, et al.: Biochemical outcome after radical prostatectomy, external beam radiation therapy, or interstitial radiation therapy for clinically localized prostate cancer. JAMA. 1998; 280: 969-74.

5. Tosoian JJ, Trock BJ, Landis P, Feng Z, Epstein JI, Partin AW, et al.: Active surveillance program for prostate cancer: an update of the Johns Hopkins experience. J Clin Oncol. 2011; 29: 2185-90.

6. Heidenreich A, Bastian PJ, Bellmunt J, Bolla M, Joniau S, Mason MD, et al. Guidelines on Prostate Cancer. European Association of Urology 2012. Available at http://www. uroweb.org/gls/pdf/08\%20Prostate $\% 20$ Cancer_LR\%20 March\%2013th\%202012.pdf

7. Yang CW, Lin TP, Huang YH, Chung HJ, Kuo JY, Huang WJ, et al:: Does extended prostate needle biopsy improve the concordance of Gleason scores between biopsy andprostatectomy in the Taiwanese population? J Chin Med Assoc. 2012; 75: 97-101.

8. Dall'Era MA, Albertsen PC, Bangma C, Carroll PR, Carter $\mathrm{HB}$, Cooperberg MR,et al.: Active surveillance for prostate cancer: a systematic review of the literature. Eur Urol. 2012; 62: 976-83.

9. Baechler R, Henríquez R, Aqueveque X, Martínez ME, Soto A: Prostate neoplasm prevalence in Talca, VII Region of Chile. Rev Med Chil. 2001; 129: 1305-10.

10. Luján M, Páez Á, Berenguer A, Rodríguez JA: Mortality due to prostate cancer in the Spanish arm of the European Randomized Study of Screening forProstate Cancer (ERSPC). Results after a 15-year follow-up. Actas Urol Esp. 2012; 36: 403-9.

11. Schröder FH, Hugosson J, Roobol MJ, Tammela TL, Ciatto S, Nelen V, et al.: Screening and prostate-cancer mortality in a randomized European study. N Engl J Med. 2009; 360: 1320-8.

12. Hugosson J, Carlsson S, Aus G, Bergdahl S, Khatami $A$, Lodding $P$, et al.: Mortality results from the Göteborg randomised population-based prostate-cancer screening trial. Lancet Oncol. 2010; 11: 725-32.

13. Lawrentschuk N, Klotz L: Active surveillance for favorablerisk prostate cancer: a short review. Korean J Urol. 2010; 51: 665-70. 
14. Conti SL, Dall'era M, Fradet V, Cowan JE, Simko J, Carroll PR: Pathological outcomes of candidates for active surveillance of prostate cancer. J Urol. 2009; 181: 162833; discussion 1633-4.

15. Thaxton CS, Loeb S, Roehl KA, Kan D, Catalona WJ: Treatment outcomes of radical prostatectomy in potential candidates for 3 published active surveillanceprotocols. Urology. 2010; 75: 414-8.

16. Beauval JB, Ploussard G, Soulié M, Pfister C, Van Agt $S$, Vincendeau $S$, et al.: Pathologic findings in radical prostatectomy specimens from patients eligible for active surveillance withhighly selective criteria: a multicenter study. Urology. 2012; 80: 656-60.

17. Iremashvili V, Pelaez L, Manoharan M, Jorda $M$, Rosenberg DL, Soloway MS: Pathologic prostate cancer characteristics in patients eligible for active surveillance: a head-to-head comparison of contemporary protocols. Eur Urol. 2012; 62: 462-8.

18. Pinthus JH, Witkos M, Fleshner NE, Sweet J, Evans A, Jewett MA, et al.: Prostate cancers scored as Gleason 6 on prostate biopsy are frequently Gleason 7 tumors at radicalprostatectomy: implication on outcome. J Urol. 2006; 176: 979-84; discussion 984.

19. Grossfeld GD, Chang JJ, Broering JM, Li YP, Lubeck DP, Flanders SC, et al.: Under staging and under grading in a contemporary series of patients undergoing radical prostatectomy:results from the Cancer of the Prostate Strategic Urologic Research Endeavor database. J Urol. 2001; 165: 851-6.

20. Koppie TM, Bianco FJ Jr, Kuroiwa K, Reuter VE, Guillonneau B, Eastham JA, et al.: The clinical features of anterior prostate cancers. BJU Int. 2006; 98: 1167-71.

Correspondence address:

Norman Zambrano Aravena, MD Department of Urology, Clinica Las Condes

Lo Fontecilla 441

Las Condes, Santiago, Chile

Fax: + 562 610-8885

E-mail: nrzambrano@yahoo.com 


\section{EDITORIAL COMMENT}

The concept of Active Surveillance in patients with Prostate Cancer still deserves much thought, but the consensus is that the choice of any conduct should be personalized and non-transferable. The safety of this decision is based on the rigor of the selection of these patients. What is the ideal patient to undergo Active Surveillance? A definitive answer to this question is yet to come! I congratulate the authors of this work as call into relevant question and show with a clear methodology, the choice of Active Surveillance, based on clinical and morphological parameters may not be the ideal way and inclusion criteria for Active Surveillance should have extreme rigor. Are the known limitations of Gleason score, making it an inaccurate predictor based on needle biopsy. This finding was observed by other authors, who described the need for treatment in over $80 \%$ of patients with stage T1c and only 16\% had insignificant tumor when compared to data from biopsy and surgical specimens (1). In this present study the authors found a rate of $31.1 \%$ of patients with Gleason score of the surgical specimen greater than obtained in needle biopsy. It is a significant data and should be valued in decision making, especially when the population studied was composed of relatively young patients, with a mean age of 62.3 years. In summary, the Active surveillance requires conditions that go beyond medical criteria as to their applicability is also required a high degree of patient information, as well as favorable psychological profile and above all ensuring access to health services, with full coverage costs. This is not easy!

\section{REFERENCE}

1. Epstein JI, Walsh PC, Carmichael M, Brendler CB: Pathologic and clinical findings to predict tumor extent of nonpalpable (stage T1c) prostate cancer. JAMA. 1994; 271: 368-74.

José Carlos de Almeida, MD Brazilian Society of Urology E-mail: jcalmeidadf@gmail.com 